\title{
Stimulus-response compatible orienting and the effect of an action not taken: Perception delayed is automaticity denied
}

\author{
DEREK BESNER and EVAN F. RISKO \\ University of Waterloo, Waterloo, Ontario, Canada
}

\begin{abstract}
Orienting to a signal source is widely viewed as automatic in the sense that it is triggered by the stimulus. However, this behavior is typically assessed in a context in which the subject knows beforehand what he or she has to do. In the present experiments, the role of task set was investigated by having the response vary randomly from trial to trial. On some trials, a cue signaled the subject to respond, and on the remaining trials, another cue signaled the subject to withhold a response. Stimulus contrast and temporal overlap between task cue and target were manipulated. The effect of a reduction in stimulus contrast was sometimes absorbed into the time taken to decode the cue, but critically, other times not. These results highlight the theoretical importance of considering task set as an essential element in processing, and they undermine the theoretical claim that putatively automatic processes are not subject to interference from other mental activities.
\end{abstract}

What is the relation between task set and automatic processing? We first define how these terms will be used here. We then consider the relation between these theoretical views in terms of how they are widely (albeit in large part implicitly) understood to be reflected in performance in one skilled domain. We then report two experiments in the perception-action domain whose results are interpreted as evidence that, at least sometimes, the relation between these two views should be understood in a different way. In particular, task set has a dominant influence on early perceptual processing, rather than being subordinate to putatively automatic processing.

\section{Automaticity \\ Automatic processing has numerous definitions. For example, in the context of skilled visual word recogni- tion, it is widely held to reflect mental processes that (1) are initiated by the stimulus, (2) are obligatory, (3) are ballistic, and (4) can operate in the absence of conscious awareness (see, e.g., T. L. Brown, Gore, \& Carr, 2002; Neely \& Kahan, 2001; and Posner \& Snyder, 1975, among many others). We concern ourselves here with the wide- spread assumptions that automatic processing is stimulus initiated and ballistic (i.e., cannot be interrupted by other mental activities).}

This work was supported by Natural Sciences and Engineering Research Council of Canada (NSERC) Grant A0998 to D.B. and by an NSERC Undergraduate Research Award to E.F.R. We thank Ulrich Mayr, two anonymous reviewers, and Tram Neill for constructive comments and Marg Ingleton for technical support. Address correspondence to D. Besner, Psychology Department, University of Waterloo, Waterloo, ON, N2L 3G1 Canada (e-mail: dbesner@watarts.uwaterloo.ca).

\section{Task Set}

Task set refers to the knowledge that a subject in an experiment has about what he or she has to do. Processing system(s) are configured so as to be able to carry out the task at hand (Rogers \& Monsell, 1995).

\section{Relation Between Automatic Processing and Task Set}

The prevailing view is that configuring various processes in order to carry out a particular task cannot prevent automatic processes from beginning and running to completion. For example, the Stroop effect, where irrelevant semantic information specified by a word interferes with identifying the color in which the word appears, is almost invariably taken as strong evidence that it is impossible to prevent the word from being identified. Semantic activation in other paradigms (e.g., the semantic priming paradigm) is also widely viewed as impossible to prevent, provided that lexical activation has occurred (Neely \& Kahan, 2001).

There are several difficulties with the conclusion that certain processes in skilled reading are automatic in the sense described above. An empirical difficulty is that there exist a number of reports that various aspects of lexical-semantic processing in the context of visual word recognition can be blocked (e.g., Bauer \& Besner, 1997; M. S. Brown, Roberts, \& Besner, 2001; Raz, Shapiro, Fan, \& Posner, 2002; Smith \& Besner, 2001; Stolz \& Besner, 1998). A broader conceptual difficulty that applies to processing in more general terms (i.e., beyond the narrow issue of whether semantic activation during reading can be blocked) has gone unrecognized, or at least has not been widely commented on. That is, in most experimental paradigms, the subject knows what he or 
she has to do before the stimulus appears. The subject is, therefore, set to do that task. This makes it difficult to decide whether any observed effects should be attributed to automatic processing, to mental set effects, or to some combination of these two possibilities.

Besner and Care (2003) developed a variant of the task choice paradigm in order to investigate whether the mere presentation of a stimulus is, as is widely assumed, sufficient to trigger processing in skilled readers. In their experiment, a letter string was presented, and the subjects had to either read it aloud or decide whether it appeared in upper- or lowercase. Information about the task was presented in the form of a colored block surrounding the letter string. One color cued one task, and another color cued the other task. The cue appeared either $750 \mathrm{msec}$ before the letter string or at the same time as the letter string, and stimuli appeared in either low contrast or high contrast. All of these conditions (task, SOA, and contrast) were randomly intermixed.

Besner and Care's (2003) logic was that if subjects were able to encode the stimulus in parallel with decoding the task cue, the effect of a reduction of stimulus contrast would be absorbed into the cognitive slack created by the time taken to decode the cue. If these two operations did not occur in parallel but, instead, occurred one after the other, additive effects of SOA and contrast were expected (see Pashler, 1994, for similar logic in the context of the psychological refractory period paradigm). Besner and Care found additive effects of stimulus onset asynchrony (SOA) and contrast on response time (RT) in both tasks and were able to rule out the possibility that the stimulus was encoded as soon as it was presented and the task cue decoded after the effect of low contrast had been dealt with. They therefore argued that, at least in the context of this particular experiment, subjects first decoded the cue so as to get set for the specific task called for on that trial. They concluded that the data undermined the widespread view that letter identification in support of phonological coding is automatic in the sense of being triggered by the stimulus and not interfered with by other mental activities (see, e.g., Frost, 2003, among many others).

Besner and Care (2003) noted that variants of the task choice paradigm could be used to investigate a variety of questions. Among them, what combination of stimuli and tasks, if any, affords automatic encoding, where automatic is defined as being triggered by stimulus presentation and not being interfered with by other mental activities.

\section{The Present Experiments}

We applied a variant of Besner and Care's (2003) task choice paradigm to a situation that is widely viewed as reflecting automatic processing. In this simple task, a stimulus appears to the left or the right of a vertical bar, and subjects respond by pressing a key on the same side as the stimulus. In other words, the perception-action loop is said to be stimulus-response compatible (Korn- blum, Hasbroucq, \& Osman, 1990). Three factors were manipulated: target contrast (bright vs. dim), SOA (task information was presented $750 \mathrm{msec}$ in advance of the target or at the same time as the target in Experiment 1; Experiment 2 added an SOA in which the target preceded the tone), and the response the subjects had to make (a tone dictating whether to make a response or to withhold one).

If processing is automatic, in that it is triggered by the stimulus and cannot be interfered with by other mental activities, a simple prediction follows. The effect of contrast present in the 750-msec SOA condition will be absent in the 0 -msec SOA condition. This is because target processing is initiated by its onset and there is time for the effect of low contrast to be absorbed into the slack associated with the time taken to decode the task cue if these two events can go on in parallel. This logic depends on cue-decoding time being longer than the time needed to deal with the effect of a reduction in stimulus contrast. In the present experiments, a crude estimate of cuedecoding time is provided by the difference in RT between the 750- and the $0-\mathrm{msec}$ SOAs, since at the $750-\mathrm{msec}$ SOA the task is known to the subject by the time the target is presented, whereas in the 0 -msec SOA condition the subject must compute what task he/she has to do in the presence of the target. The average difference in RT between the 750- and the 0 -msec SOAs is approximately five times larger than the effect of the contrast manipulation, so the logic holds.

One other question is of immediate interest. If underadditivity is observed, will it be modulated by the response set on the previous trial? For example, subjects might employ a strategy of maintaining the response set that was applied on the last trial. It is thus important to separately consider switch trials (in which the current trial required a go response and the previous trial required the subject to withhold a response) and repeat trials (in which the response was to go on both the current and the previous trials).

To anticipate the results, the outcome of these experiments does not support an account in which target processing is initiated by its onset and is not subject to interference from other mental activities. Task set plays a much more extended role than generally considered, even in early perceptual processing. Indeed, at least sometimes, functional processing waits until the appropriate task set is known.

\section{EXPERIMENT 1}

\section{Method}

Subjects. Thirty-four undergraduate students were paid $\$ 4$ each for their participation. All the subjects reported normal or correctedto-normal vision.

Apparatus. Micro Experimental Lab Version 2.0 (Schneider, 1988) software controlled the timing and presentation of stimuli and logged responses and RTs. The stimuli were presented to the subjects on a standard 15-in. SVGA color monitor.

Design. The experimental design consisted of a 2 (SOA: 0 vs. $750 \mathrm{msec}) \times 2$ (contrast: bright vs. $\operatorname{dim}) \times 2$ (trial type: switch vs. 
repeat) within-subjects design. The SOA and the contrast factors were completely crossed. The trial type factor (i.e., whether the response set was repeated or was switched on successive trials) was calculated post hoc.

Stimuli. The stimulus display consisted of a fixation symbol ( | ), $1 \mathrm{~cm}$ vertically and $0.2 \mathrm{~cm}$ horizontally, located in the center of the display. A filled disk $(\bullet), 0.5 \mathrm{~cm}$ vertically and horizontally, was used as the target. The targets appeared $1.2 \mathrm{~cm}$ to the left or the right of the fixation symbol and were equally likely to appear in either location. Half of the target disks appeared bright (RGB values: 63, 63, 63), and the other half $\operatorname{dim}$ (RGB values: 7, 7, 7). A tone on each trial signaled either a go trial (respond) or a no-go trial (withhold the response). For half the subjects, a high-frequency tone $(2150 \mathrm{~Hz})$ signaled go, and a low-frequency tone $(400 \mathrm{~Hz})$ signaled no go. The remaining subjects were assigned to the reversed mapping. The subjects viewed the monitor from a distance of approximately $60 \mathrm{~cm}$, where $1 \mathrm{~cm}$ is approximately equal to $1^{\circ}$ of visual angle. All the stimuli were presented on a black background.

Procedure. The subjects were tested individually in a dimly lit room. The subjects were instructed that, on each trial, a tone would sound and a target would appear either to the left or to the right of fixation. Depending on the tone, the subjects either localized the target by pressing the " $z$ " key if the target appeared on the left or the "/" key if the target appeared on the right or withheld a response to the target.

Each trial began with the presentation of the fixation symbol. After $500 \mathrm{msec}$, a 100-msec tone sounded. On 0-msec SOA trials, the target and the tone were presented simultaneously, and on 750-msec SOA trials, the target was presented $750 \mathrm{msec}$ after the tone. The target remained on the screen until a response was made or 1,500 msec elapsed. Following a response or a nonresponse, an intertrial interval of $1,000 \mathrm{msec}$ ensued in which the fixation symbol was presented. The fixation symbol disappeared for $250 \mathrm{msec}$ and reappeared to signal the beginning of a new trial. The subjects performed 240 experimental trials preceded by one block of 24 practice trials. If the subjects did not answer $22 / 24$ correctly in the practice block, they repeated the block until the criterion was met.

\section{Results}

An RT analysis was conducted for go trials in which the response was correct. These data were first subjected to a recursive trimming procedure that removed outliers on the basis of a criterion cutoff set independently for each subject in each condition by reference to the sample size in that condition (Van Selst \& Jolicœur, 1994). This trimming procedure resulted in $2.4 \%$ of the RT data being discarded. A 2 (contrast: bright or $\operatorname{dim}) \times 2$ (SOA: 0 or $750 \mathrm{msec}) \times 2$ (trial type: switch or repeat) analysis of variance (ANOVA) was conducted on the RTs. These data are presented in the top panel of Figure 1.

RTs. The subjects responded more slowly on dim trials $(492 \mathrm{msec})$ than on bright trials $[460 \mathrm{msec} ; F(1,33)=$ $\left.27.78, M S_{\mathrm{e}}=2,501.04, p<.01\right]$, more slowly on 0 -msec SOA trials $(564 \mathrm{msec})$ than on 750 -msec SOA trials $\left[389 \mathrm{msec} ; F(1,33)=214.86, M S_{\mathrm{e}}=9,643.94, p<.01\right]$,

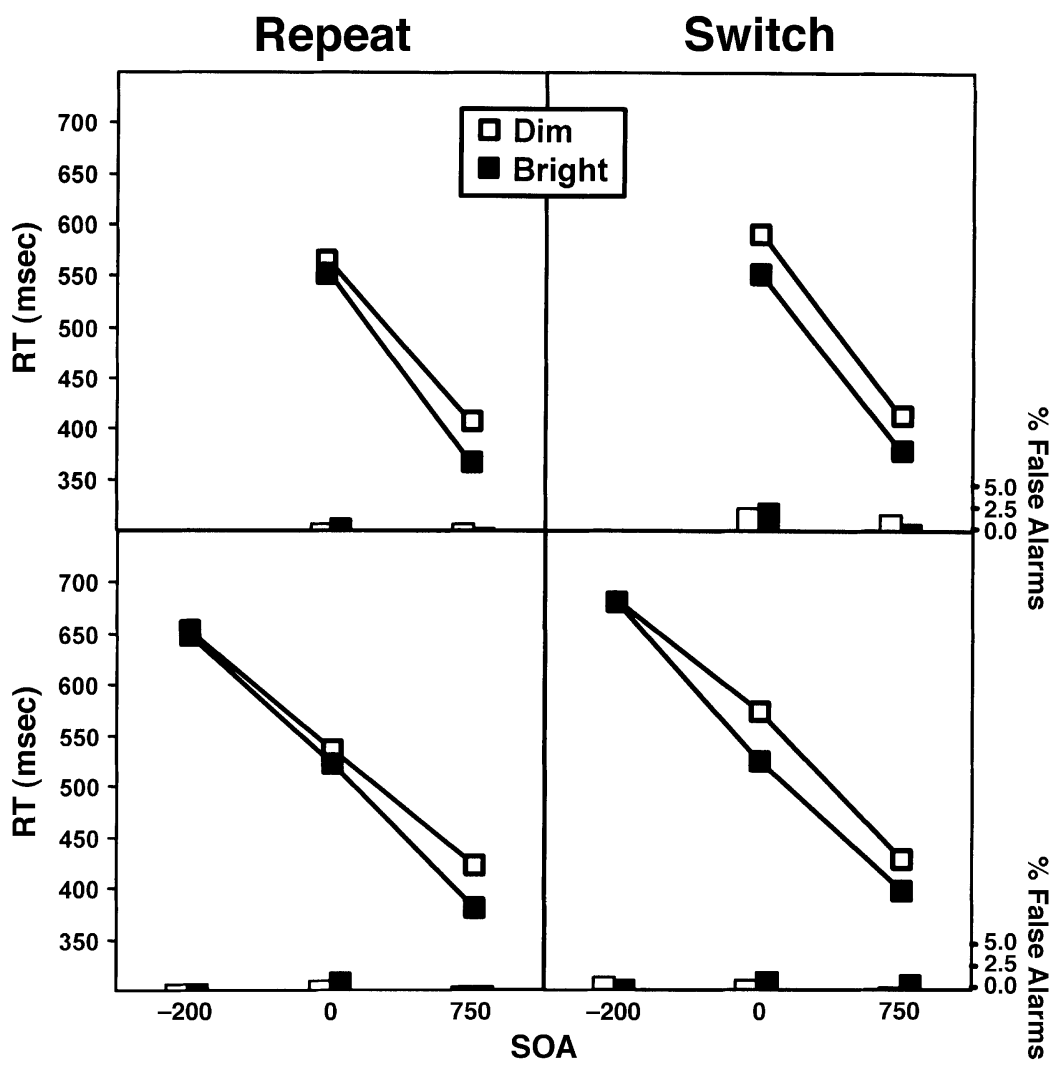

Figure 1. Mean response times (RTs, in milliseconds) for go trials and percentages of false alarms for no-go trials in Experiment 1 (top panel) and Experiment 2 (bottom panel). 
and more slowly on switch trials (485 $\mathrm{msec})$ than on repeat trials $\left[468 \mathrm{msec} ; F(1,33)=8.67, M S_{\mathrm{e}}=2,323.41\right.$, $p<.01]$. The three-way interaction between contrast, SOA, and trial type was significant $[F(1,33)=6.94$, $\left.M S_{\mathrm{e}}=664.32, p<.05\right]$. A pair of two-way follow-up ANOVAs (contrast $\times$ SOA) was performed: one on repeat trials and one on switch trials. The SOA $\times$ contrast interaction was significant on repeat trials $[F(1,33)=$ $\left.7.58, M S_{\mathrm{e}}=863.72, p<.05\right]$, but not on switch trials $(F<1)$.

Errors. There were three types of errors: (1) localization errors, in which the subjects responded incorrectly on a go trial, (2) misses, in which the subjects withheld a response on a go trial, and (3) false alarms, in which the subjects responded on a no-go trial. Localization errors $(0.2 \%)$ and misses $(0.5 \%)$ were so infrequent that no further analysis was conducted. A 2 (contrast) $\times 2(\mathrm{SOA}) \times$ 2 (trial type) ANOVA was conducted on the false alarm data.

False alarms. The subjects committed more false alarms at the 0 -msec SOA (1.8\%) than at the 750 -msec SOA $\left[0.8 \% ; F(1,33)=6.95, M S_{\mathrm{e}}=9.60, p<.05\right]$ and committed more false alarms on switch trials $(2.0 \%)$ than on repeat trials $\left[0.7 \% ; F(1,33)=11.88, M S_{\mathrm{e}}=\right.$ $9.13, p<.01]$. No other effects were significant (all $p \mathrm{~s}>.1$ ). The minimally higher false alarm rate for switch trials at the 0 -msec SOA suggests that the task cue may not always have been decoded.

\section{Discussion}

The results of Experiment 1 are straightforward. Contrast was underadditive with SOA, as predicted by the automatic processing perspective, but only when the task was the same as that on the immediately preceding trial. When the task was switched from withholding a response on trial $n-1$ to making an overt response on trial $n$, contrast and SOA on trial $n$ had statistically additive effects on RT. This three-way interaction limits the joint assertion that functional processing both is initiated by the stimulus and cannot be interrupted by other mental activities.

These results will be discussed further following Experiment 2. This experiment was identical to Experiment 1, except for the addition of another SOA in which the target appeared $200 \mathrm{msec}$ before the tone. When the target appears prior to the tone, there is sufficient time to deal with the effects of a reduction in contrast and, perhaps, to do some preparation associated with a response. The expectation, therefore, was that relative to the $750-\mathrm{msec}$ SOA, contrast would be underadditive in this condition, even when the task on the present trial switched, relative to the previous trial. The further question was whether the presence of a negative SOA, which yields underadditivity of SOA and contrast, would provide a context that promoted processing at the 0 -msec SOA, which would differ from that seen in the switch condition in Experiment 1 . If underadditivity between contrast and SOA was now also seen in the switch condition, this would be taken to imply that what was observed in Experiment 1 was the result of strategic processing. If the three-way interaction seen in Experiment 1 persisted, this would suggest that the 0 -msec SOA switch condition presents a more fundamental difficulty for the subject.

\section{EXPERIMENT 2}

\section{Method}

Thirty undergraduate students participated in Experiment 2. The apparatus, design, stimuli, and procedure were the same as those in Experiment 1, except for the addition of the $-200-\mathrm{msec}$ SOA. The subjects performed 240 experimental trials, preceded by a block of 48 practice trials. If the subjects did not answer $43 / 48$ correctly in the practice block, they repeated the block until the criterion was met.

\section{Results}

Analyses were conducted in the same manner as in Experiment 1. The outlier procedure resulted in $3.0 \%$ of the RT data being discarded. A 2 (contrast) $\times 3$ (SOA) $\times$ 2 (trial type) ANOVA was conducted on RTs. The data for Experiment 2 are presented in the bottom panel of Figure 1.

RTs. Critically, the contrast $\times \mathrm{SOA} \times$ trial type interaction was significant $\left[F(1,58)=4.38, M S_{\mathrm{e}}=1,041.06\right.$, $p<.05]$. Figure 1 shows that there was a negligible effect of contrast at the -200 -msec SOA for both repeat $(3 \mathrm{msec})$ and switch $(2 \mathrm{msec})$ trials. The -200 -msec SOA was therefore dropped, and a pair of 2 (contrast) $\times$ 2 (SOA) ANOVAs were carried out for repeat and switch trials separately. As in Experiment 1, the SOA $\times$ contrast interaction was significant on repeat trials $[F(1,29)=$ $\left.4.65, M S_{\mathrm{e}}=1,246.51, p<.05\right]$, but not on switch trials $\left[F(1,29)=2.32, M S_{\mathrm{e}}=1,196.05, p>.16\right]$.

Errors. Localization errors (0.1\%) and misses $(0.2 \%)$ were so infrequent that no further analysis was conducted. A 2 (contrast) $\times 3(\mathrm{SOA}) \times 2$ (trial type) ANOVA was conducted on false alarms.

False alarms. There was a marginal effect of SOA $\left[F(2,58)=2.61, M S_{\mathrm{e}}=8.38, p<.09\right]$, in which more false alarms were seen at the $0-\mathrm{msec}$ SOA $(1.4 \%)$ than at either the -200 -msec SOA $(0.9 \%)$ or the 750 -msec SOA $(0.6 \%)$. No other effects approached significance (all $\left.F_{\mathrm{S}}<1.4\right)$.

\section{Discussion}

There are two important results from Experiment 2. First, when the target preceded the cue by $200 \mathrm{msec}$, there was sufficient time to identify the stimulus before the cue appeared and hence, there was no contrast effect. This was true for both repeat and switch trials.

Second, the triple interaction seen in Experiment 1 was again observed in Experiment 2. Namely, contrast and SOA were underadditive on RT, provided that the prior trial also called for a go response. Indeed, on repeat trials at the 0 -msec SOA, virtually all of the contrast effect was absorbed into the cognitive slack created by the time taken to decode the cue. However, if the immediately prior trial called for a no-go response, contrast and SOA were additive on RT. In short, the 0 -msec SOA condition, when combined with a switch from withholding a response to making an overt response, created a 
particular difficulty for the subject. It remains to be determined whether this is structural or strategic.

Our favored explanation ${ }^{1}$ for (1) the underadditive interaction between contrast and SOA on repeat trials and (2) the additive effects of contrast and SOA on switch trials rests on two assumptions. First, the set that is in place on the current trial is the set that was used on the last trial, and second, subjects compare the cue on the current trial with the cue on the prior trial (see also Logan $\&$ Bundesen, 2003). When the cues match, the set already in place allows functional processing to unfold, and the effect of contrast is absorbed into the cognitive slack associated with this matching process. However, when there is a mismatch (i.e., a switch trial), subjects first reconfigure the task set and then recompute their perceptual processing from scratch. The consequence is the elimination of the underadditive interaction between SOA and contrast. In short, if the default set (maintained from the previous trial) is not appropriate, then, functionally speaking, no processing gets done on the target until the appropriate task set is in place.

One further point is worthy of brief comment. The different pattern of results from the task used here and the naming/case tasks reported in Besner and Care (2003; relatedly, see Oriet \& Jolicœur, 2003) illustrates that these same factors (contrast and SOA) can behave quite differently in different contexts. However, it should be noted that in Besner and Care's experiment (and in Oriet \& Jolicœur), subjects had to perform one of two different cognitive tasks on a trial, whereas in the present experiments, the same task was always called for, but the response varied. It remains to be seen whether any underadditivity between contrast and SOA would be observed if subjects were given only one task (e.g., name the letter string) but, as here, had to either make an overt response or withhold one.

The most general conclusion to be drawn from the present results is that even for quite primitive perceptualmotor acts, mental set exerts a powerful effect on performance. In particular, the results from the switch trials, taken in conjunction with the results from the repeat condition, undermine the widespread view that functional processing of the target is initiated simply by the onset of the stimulus.

\section{REFERENCES}

Bauer, B., \& Besner, D. (1997). Processing in the Stroop task: Mental set as a determinant of performance. Canadian Journal of Experimental Psychology, 51, 61-68.

BESNER, D., \& CARE, S. (2003). A paradigm for exploring what the mind does while deciding what it should do. Canadian Journal of Experimental Psychology, 57, 311-320.

Brown, M. S., Roberts, M. A., \& Besner, D. (2001). Semantic processing in visual word recognition: Activation blocking and domain specificity. Psychonomic Bulletin \& Review, 8, 778-784.

Brown, T. L., Gore, C. L., \& CARR, T. H. (2002). Visual attention and word recognition in Stroop color naming: Is word recognition "automatic"? Journal of Experimental Psychology: General, 131, 220-240.
Frost, R. (2003). The robustness of phonological effects in fast priming. In S. Kinoshita \& S. J. Lupker (Eds.), Masked priming: The state of the art (pp. 173-191). New York: Psychology Press.

Kornblum, S., HasbroucQ, T., \& Osman, A. (1990). Dimensional overlap: Cognitive basis for stimulus-response compatibility-a model and taxonomy. Psychological Review, 97, 253-270.

LogAN, G. D., \& BundeSEN, C. (2003). Clever homunculus: Is there an endogenous act of control in the explicit task cuing procedure? Journal of Experimental Psychology: Human Perception \& Performance, 29,575-599.

NEELY, J. H., \& KAHAN, T. A. (2001). Is semantic activation automatic? A critical re-evaluation. In H. L. Roediger III, J. S. Nairne, I. Neath, \& A. M. Surprenant (Eds.), The nature of remembering: Essays in honor of Robert G. Crowder (pp. 69-93). Washington, DC: American Psychological Association.

Oriet, C., \& Jolicceur, P. (2003). Absence of perceptual processing during reconfiguration of task set. Journal of Experimental Psychology: Human Perception \& Performance, 29, 1036-1049.

PASHLER, H. (1994). Dual-task interference in simple tasks: Data and theory. Psychological Bulletin, 116, 220-244.

Posner, M. I., \& SNYDER, C. R. (1975). Attention and cognitive control. In R. L. Solso (Ed.), Information processing and cognition: The Loyola Symposium (pp. 55-85). Hillsdale, NJ: Erlbaum.

Raz, A., Shapiro, T., FAn, J., \& Posner, M. I. (2002). Hypnotic suggestion and the modulation of Stroop interference. Archives of General Psychiatry, 59, 1155-1161.

Rogers, R. D., \& MONSELL, S. (1995). Costs of a predictable switch between cognitive tasks. Journal of Experimental Psychology: General, 124, 207-231.

SCHNEIDER, W. (1988). Micro Experimental Laboratory: An integrated system for IBM PC compatibles. Behavior Research Methods, Instruments, \& Computers, 20, 206-217.

Smith, M. C., \& Besner, D. (2001). Modulating semantic feedback in visual word recognition. Psychonomic Bulletin \& Review, 8, 111-117.

Stolz, J. A., \& Besner, D. (1998). Levels of representation in visual word recognition: A dissociation between morphological and semantic processing. Journal of Experimental Psychology: Human Perception \& Performance, 24, 1642-1655.

VAN SELST, M., \& JolicEUR, P. (1994). A solution to the effect of sample size on outlier estimation. Quarterly Journal of Experimental Psychology, 47, 631-650.

\section{NOTE}

1. A different possibility is that the underadditive interaction between contrast and SOA on repeat trials arises entirely from those trials in which the location of the target on the last trial is the same as that on the current trial and both trials require a go response. Under these conditions, a response may be retrieved from memory, rather than being generated on line. If so, the underadditive interaction between contrast and SOA should be confined to such repetitions. This possibility was assessed with a $2 \times 2 \times 2$ ANOVA with contrast (dim or bright), SOA ( 0 or $750 \mathrm{msec}$ ), and target location (same or different across the current and the immediately previous trial). Stimulus-response repetition was calculated post hoc and resulted, on average, in half the number of observations per cell from previous analyses. To improve power, the subjects from both experiments were entered into a single within-subjects ANOVA. This analysis yielded a marginal main effect of stimulus location/response repetition $\left[F(1,63)=3.45, M S_{\mathrm{e}}=3,031.36, p<.07\right]$, in which subjects were slower on trials in which the target location repeated $(474 \mathrm{msec})$ than when it did not $(465 \mathrm{msec})$. The contrast $\times$ SOA interaction was significant $\left[F(1,63)=10.69, M S_{\mathrm{e}}=2,042.80, p<.01\right]$ and was not modulated by stimulus repetition. That is, the three-way interaction was not significant $(F<1)$. This analysis thus provides no support for this alternative account.

(Manuscript received February 9, 2004; revision accepted for publication May 24, 2004.) 